\title{
SOP: First-ever epileptic seizure in adult patients
}

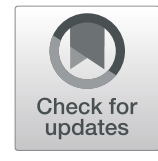

Julian Bösel ${ }^{1,2}$ (D)

\begin{abstract}
Background: About 5\% of all adults will have at least one epileptic seizure in their life. The incidence of all unprovoked seizures ranges from approximately 50 to $70 / 100,000$. The very first epileptic seizure in an adult can be a very decisive event and demands a great deal of responsibility on the part of the treating clinician. Optimal clinical work-up and systematic decision-making are necessary to ensure adequate treatment as well as to avoid unnecessary treatment, such as life-long application of anticonvulsants that may not be indicated.
\end{abstract}

Aim: To present a pragmatic standard operating procedure (SOP) for approaching the first seizure in adults.

Method: Based on current recommendations and personal suggestions, an SOP in the form of a flow chart accompanied with topical explanations and tables was created.

Results: Approaching the first seizure should start with obtaining bystander information on the seizure and its clinical features. Then, differential diagnoses should be considered. The diagnostic work-up hast to contain a neurological and physical examination, emergency blood tests and cerebral imaging. This should allow to differentiate an unprovoked from an acute symptomatic seizure, i.e. triggered by current specific and identifiable structural or metabolic cause that should be eliminated if possible. In the case of an unprovoked seizure, estimation of seizure recurrence is necessary for the decision to start treatment with antiepileptic drugs.

Conclusion: The challenge of diagnostic work-up and treatment decisions after a first epileptic seizure in adults may be facilitated by a systematic, SOP-based approach.

\section{Introduction}

About $5 \%$ of all adults will have at least one epileptic seizure in their life. The incidence of all unprovoked seizures ranges from approximately 50 to $70 / 100,000$ and that of epilepsy from 30 to $50 / 100,000$ in the USA, UK or Europe [1]. The very first epileptic seizure in an adult can be a very decisive event and demands a great deal of responsibility on the part of the treating clinician. Statistically, it takes about four years in average until that person regains "normality" in both private and professional life, even if that first seizure is not followed by more. Optimal clinical work-up and systematic decision-making are necessary to ensure adequate treatment as well as to avoid unnecessary treatment, such as life-long application of anticonvulsants that may not be

\footnotetext{
Correspondence: julian.boesel@klinikum-kassel.de

${ }^{1}$ Department of Neurology, Klinikum Kassel, Mönchebergstr. 41-43, 34125 Kassel, Germany

${ }^{2}$ Kassel School of Medicine, University of Southampton, Mönchebergstr. 41-43, 34125 Kassel, Germany
}

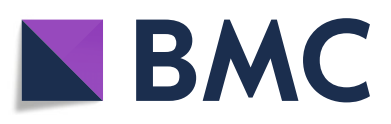

(c) The Author(s). 2019 Open Access This article is distributed under the terms of the Creative Commons Attribution 4.0 International License (http://creativecommons.org/licenses/by/4.0/), which permits unrestricted use, distribution, and

reproduction in any medium, provided you give appropriate credit to the original author(s) and the source, provide a link to the Creative Commons license, and indicate if changes were made. The Creative Commons Public Domain Dedication waiver (http://creativecommons.org/publicdomain/zero/1.0/) applies to the data made available in this article, unless otherwise stated.

indicated. Because such work-up and decision-making is challenging and in several aspects controversial, dedicated first seizure clinics have been suggested and introduced in some countries [2]. The following standard operating procedure (SOP) will mainly cover the initial approach to an adult patient with a first seizure in the emergency room and the first days after admission, as based on current recommendations [3-5]. It is, however, not reflecting a particular guideline or approved by an expert committee, hence contains subjectivity to some degree. Further aspects such as details of drug choice, psychosocial adjunctive treatment, limitations of daily activities / profession / driving, etc. are beyond the scope of this article and will just be briefly addressed by reference to the current literature. Also, pediatric seizures are not discussed here. A very informative and practical approach along guiding questions can be found in this review: [6]. 


\section{Definitions Epilepsy}

Chronic brain disease that is characterized by at least one of these conditions: 1 . At least two unprovoked seizures or reflex-seizures with an interval of at least $24 \mathrm{~h} ; 2$. An unprovoked seizure with a recurrence risk of at least $60 \%$; 3 . The diagnosis of a specific epilepsy syndrome $[3,4]$.

\section{Epileptic seizure}

Transient clinical signs or symptoms due to a pathologic excessive or (over-)synchronized neuronal activity in the brain [3].

\section{Acute symptomatic seizure}

Seizures that result from some immediately recognizable stimulus or cause, i.e. that occur in the presence or close timely association (about a week) with an acute brain insult (metabolic, toxic, structural, infectious, hypoxic, etc.) [7].

\section{Unprovoked seizure}

Seizures that do not require an immediate precipitating event, suggesting the possibility of an underlying neurological disorder and may particularly predispose to recurrent seizures [8].

\section{First things first: Immediate measures}

- Check and secure vital functions

- Get a (medical) history from observer(s)

- Don't use / prescribe anticonvulsants prematurely

\section{Flow chart SOP first seizure in adults}

(Figure 1)

\section{Comments, explanations, additions (see footnotes in flow chart)}

1. Quite often, the seizure has not been witnessed by the treating physician himself, and not even the emergency physician or paramedics presenting the patient. It is then of paramount importance to obtain a detailed description from eye witnesses. Today, pictures or movies taken by smartphones may also be very helpful. This may allow to recognize particular features of a seizure (i.e. involuntary repetitive and/or extending motoric and/or sensoric phenomena with or without disturbance or loss of consciousness) and even differentiate the type (generalized / focal, tonic / clonic / tonic-clonic /..., etc.). It should especially be asked whether the seizure was focally initiated (e.g. by head turn, which strongly suggests a focal onset) and how the eyes appeared (closed: rather non-epileptic seizure, upward deviation: rather syncope, open / "staring" and mid-position or sideward deviation: rather epileptic seizure). Another very important feature is whether the patient displayed a delayed or even prolonged re-awakening and re-orientation, which often reflects the post-ictal phase after a true epileptic seizure.

2. Misdiagnosis in suspected seizures is common (20-30\%). Differential diagnoses may be grouped according to the age of the patient: In young adults, these may be vasovagal syncope, narcolepsy, paroxysmal dyskinesia, Tic, migraine with aura, panic attacks, hypnic myoclonus as a physiological sleep related phenomenon. In the elderlies, these may rather be cardiogenic syncope, transient ischemic attack, transient global amnesia, drop attacks, delirium, and toxic-metabolic encephalopathies, as well as REM- / Non-REM sleeping disorder. In both age groups, dissociative seizures (non-epileptic / psychogenic seizures) may occur (estimated incidence 5-30 / 100,000) and pose the greatest challenge in differentiation. Of note, the majority of syncopes is convulsive! See Table 1 for an overview of more frequent differential diagnoses (Table 1)

3. The neurological examination may yield ongoing signs of seizure activity (tonic / myoclonic convulsions, (orofacial) automatisms, loss of consciousness, etc.), postictal disturbance of consciousness, focal deficits indicative of an epileptogenic brain lesion, or be absolutely normal. A systemic physical inspection and examination may yield indicators of seizure-provoking factors (infection, drug / alcohol abuse, chronic disease, etc.), traumatic consequences of a seizure (fractures, luxations, bruises, open injuries, etc.), and possible seizure-assocations (enuresis, tounge bite (laterally!), muscle soreness, etc.), although the latter are often non-specific.

4. Emergency laboratory work-up may yield infectionrelated, metabolic or electrolyte derangements that may have triggered the seizure. These may constitute a criterion for an acute symptomatic seizure [7]. Drug abuse or toxicity may cause about 3\% of firstever seizures and may call for toxicology screening if suspected. In the past, prolactine levels were sometimes measured as an indicator for a true epileptic seizure, however, these turned out to be non-specific. Creatinine kinase may rise to indicate a convulsive seizure, but this can occur quite delayed and is, again, non-specific, as it may just be associated with trauma from a fall or convulsions from a syncope. It should still be part of the blood test to be integrated with other results. In the case of a series of seizures or even status epilepticus, creatinine kinase may rise massively and reach dangerous levels demanding nephroprotective fluid therapy. 
SOP First-ever seizure in adults

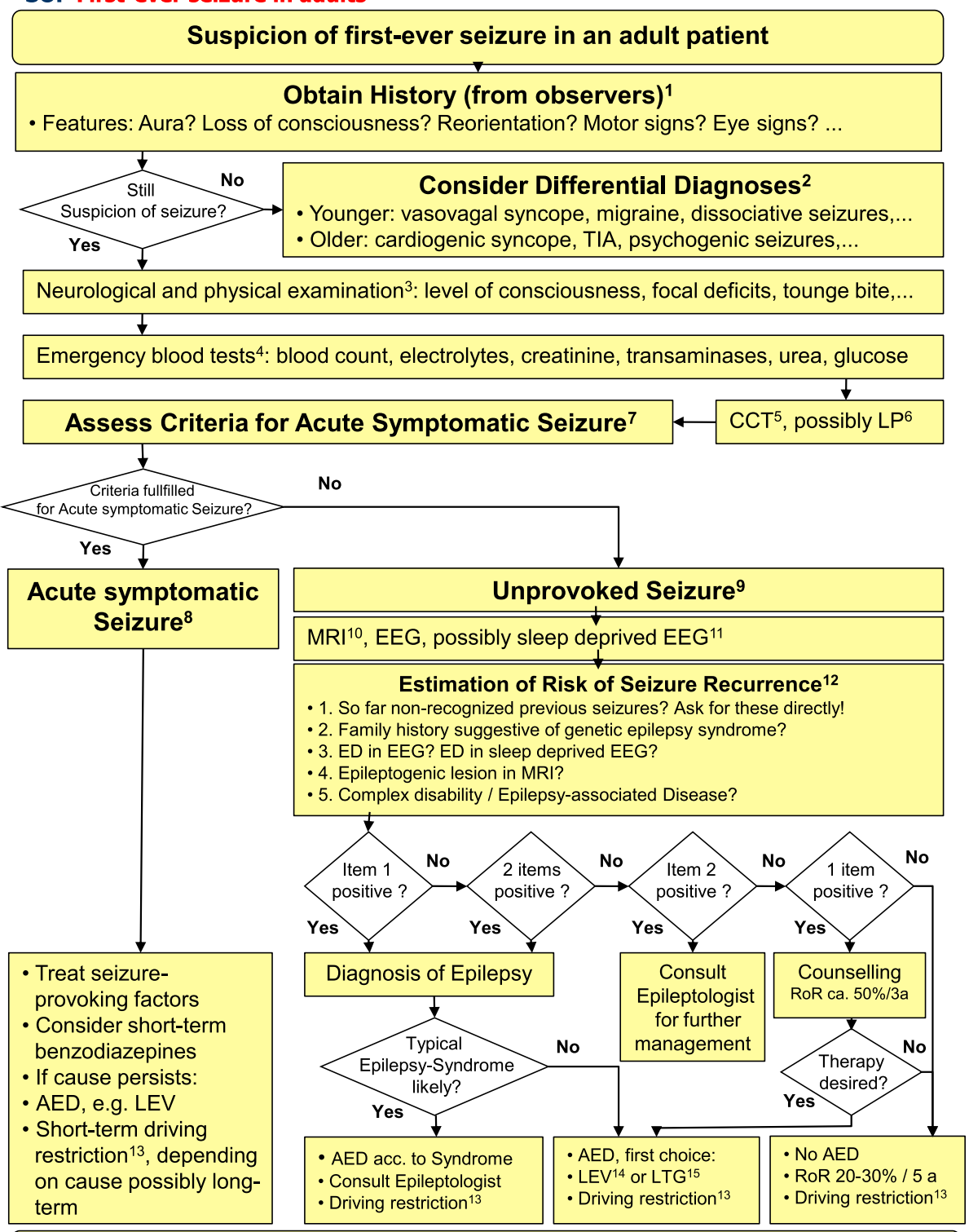

Aim for admission to ward and/or assignment to first seizure clinic ${ }^{16}$

Fig. 1 Suggestion of a step-wise standardized approach to a first-ever epileptipc seizure in adults. For abbreviations, see list at end of article

5. Every patient with a first-ever seizure should receive cerebral imaging. If magnetic resonsance imaging (MRI) is not available acutely, as is often the case, cranial computed tomography (CCT) should be applied to rule out or detect direct or indirect signs of pathologies such as acute ischemic or hemorrhagic stroke, large tumor, CVST, etc. Its average yield of cerebral abnormalities after a first seizure is about $10 \%$. $\mathrm{CCT}$ in the emergency room should definitely be done in patients older than 40 years, partial onset seizures, ongoing altered mental state, recent trauma, known cancer, anticoagulation, immunodeficiency, fever, and focal neurological deficits. MRI should then be added as soon as feasible.

6. Clinical and/or laboratory signs of meningitis or encephalitis demand a lumbar puncture. Initial basic CSF work-up for infections may later be followed by antineuronal antibody-tests in suspected autoimmune-encephalitis, hence portions of CSF should be stored.

7. Acute symptomatic seizures (ASS) have an incidence of about 20-30 / 100,000 and constitute about $40 \%$ of all afebrile seizures in the population. Suggested criteria for an ASS are: 1. Acute ischemic stroke / intracerebral 
Table 1 Selected differential diagnoses (modified from [12])

\begin{tabular}{|c|c|c|c|c|c|c|}
\hline & Epileptic Seizure & Syncope & Dissociative Seizure & Parasomnia & $\begin{array}{l}\text { Paroxysmal Movement } \\
\text { Disorder }\end{array}$ & Migraine (aura) \\
\hline Duration & $30-120 \mathrm{~s}$ & $10-30 \mathrm{~s}$ & seconds to hours & seconds to minutes & seconds to hours & 4 to $72 \mathrm{~h}$ \\
\hline Eyes & open & open & (tightly) closed & open & open & open \\
\hline $\begin{array}{l}\text { Motor } \\
\text { signs }\end{array}$ & $\begin{array}{l}\text { automatisms, } \\
\text { tonic, clonic, } \\
\text { versive, } \\
\text { tonic-clonic }\end{array}$ & $\begin{array}{l}\text { irregular } \\
\text { myoclonic } \\
\text { and tonic } \\
\text { convulsions }\end{array}$ & $\begin{array}{l}\text { crescendo and } \\
\text { decrescendo, } \\
\text { variability from } \\
\text { event to event }\end{array}$ & $\begin{array}{l}\text { few targeted } \\
\text { automatisms }\end{array}$ & $\begin{array}{l}\text { dystonia, dyskinesia } \\
\text { (athetotic, choreatic) }\end{array}$ & $\begin{array}{l}\text { normal (exception: } \\
\text { hemiplegic migraine) }\end{array}$ \\
\hline Speech & $\begin{array}{l}\text { ictal aphasia } \\
\text { (dominant } \\
\text { hemisphere) }\end{array}$ & $\begin{array}{l}\text { no abnormalities } \\
\text { after syncope }\end{array}$ & stuttering & no abnormality & possibly abnormality & no abnormality \\
\hline Initiation & $\begin{array}{l}\text { possibly aura } \\
\text { (seconds) }\end{array}$ & $\begin{array}{l}\text { vegetative } \\
\text { prodromi } \\
\text { (min.) }\end{array}$ & $\begin{array}{l}\text { varies, possibly } \\
\text { prodromal } \\
\text { spells }\end{array}$ & none & $\begin{array}{l}\text { tension oder } \\
\text { paraesthesia }\end{array}$ & possibly aura \\
\hline $\begin{array}{l}\text { Re- } \\
\text { orientation }\end{array}$ & often delayed & rapidly & $\begin{array}{l}\text { often delayed and } \\
\text { "stuttering" }\end{array}$ & $\begin{array}{l}\text { none if returns to } \\
\text { sleep }\end{array}$ & rapidly & gradually \\
\hline EEG & $\begin{array}{l}\text { epileptiform } \\
\text { discharges } \\
\text { (or normal) }\end{array}$ & $\begin{array}{l}\text { normal (or } \\
\text { general } \\
\text { slowing) }\end{array}$ & normal & $\begin{array}{l}\text { certain patterns from } \\
\text { Non-REM or REM-sleep }\end{array}$ & normal & $\begin{array}{l}\text { normal (or non-specific } \\
\text { slowing) }\end{array}$ \\
\hline Triggers & $\begin{array}{l}\text { rarely, then } \\
\text { stereotype } \\
\text { (e.g., flicker light) }\end{array}$ & $\begin{array}{l}\text { shock, pain, } \\
\text { micturition, } \\
\text { etc. }\end{array}$ & suggestion & drugs & $\begin{array}{l}\text { possibly physical } \\
\text { activity, coffeine, tea, } \\
\text { training }\end{array}$ & $\begin{array}{l}\text { stress, hormones, red } \\
\text { wine, etc. }\end{array}$ \\
\hline
\end{tabular}

hemorrhage; 2 . Traumatic brain injury; 3 . Hypoxic encephalopathy; 4. Post intracranial surgery; 5. Subdural hematoma, 6. Acute CNS infection or inflammation; 7. Metabolic derangement; 8. Drug / alcohol withdrawal (last consumption 7-48 h ago) [7]. Of note, sleep deprivation, although a well-known seizureprovoking factor, does not belong to these criteria. Because it was shown that the recurrence rate of seizures following a first seizure with such trigger is considerably higher than that of ASS, the International League Against Epilepsy (ILAE) recommends against considering seizures following sleep-deprivation as "provoked" seizures.

8. ASS have a similar life-time prevalence as unprovoked seizures (10\%). In $20-30 \%$ of cases, ASS may constitute the beginning of an epilepsy, and patients with a known epilepsy syndrome may present with additional ASS. Antiepileptic drug (AED) therapy is not always necessary in ASS if the causative factor can be removed. If not, or at least temporarily, AED may be initiated and those with few side effects and interactions are to be preferred.

9. Whether or not AED treatment should be started after a first unprovoked seizure is a current controversial debate. That decision is always an individual one and carries a lot responsibility. This remains true despite more recent and more directive recommendations have been published, e.g. to treat seizures associated with a lesion on MRI or clear epileptiform discharges on EEG (5).
The advantages to prevent further seizures have to be balanced against potential side effects of a life-long therapy that may not be necessary. Although AED treatment clearly reduces seizure recurrence within the next two years - which may be very relevant to an individual patient - it does not seem to change the long-term course of epilepsy [5].

10. Soon after the first seizure, magnetic resonance imaging (MRI) should be performed, since its yield of seizure-causing lesions (e.g. mesial temporal sclerosis, cortical dysplasias, arteriovenous malformations, microangiopathies, or tumors) is clearly higher than that of CCT. For a suggested MRI protocol, see ASA Table 2

(Table 2, see also [9]).

11. Electroencephalography (EEG) may start with a standard rountine investigation. The yield of abnormalities in a routine EEG is about 50\% within the first $24 \mathrm{~h}$ and about $30 \%$ beyond that

Table 2 Suggestions for an MRI protocol after first seizure or in epilepsy. Slice width $4 \mathrm{~mm}$ and less, contrast medium if lesion is found

\begin{tabular}{lll}
\hline Sequence & Slice & Orientation \\
\hline T1 & sagittal & standard \\
T2-TSE & axial & standard \\
FLAIR & axial/coronal & standard \\
T1 & coronal & standard \\
T2-TSE & coronal & temporally \\
& & angulated \\
\hline
\end{tabular}


time window. Only clear epileptiform discharges (ED) that can be differentiated from artifacts in association with clinical seizures have a diagnostic and prognostic meaning. The absence of ED does not exclude the presence of epilepsy. The sensitivity of four standard EEGs in seizure-free intervals is about $70-80 \%$. Instead of adding more standard EEGs after normal findings, a sleep deprived EEG or a long-duration video-EEG should rather be applied to enhance the yield. A sleep deprived EEG may raise a $40 \%$ yield of a routine EEG to about $60 \%$.

12. The flow chart contains a simplified suggestion for estimation of the risk of recurrence. A more recent meta-analysis of ten high-quality studies found an overall risk of recurrence after a first unprovoked seizure of $37 \%$ at 2 years. The following four factors were particularly predictive (relative risk): prior brain insult (2.6), epileptiform abnormailties on EEG (2.2), abnormal brain imaging (2.1), and nocturnal seizures (2.1, however 95\% CI 1.0-4.3). These results were incorporated in a recent guideline on that matter [10]. On direct questioning, about a third of patients with an assumedly first seizure have had absences, myoclonus, or auras in the past. Obtaining a detailed family history and a peripartal history is crucial, too, although this should certainly not be the only factor to drive AED treatment of a first seizure.

13. Driving restrictions after a first seizure differ considerably from country to country and even between states in a particular country. A reasonable driving restriction after an ASS may be 3-6 months while it may be one or more year(s) after an unprovoked seizure depending on the estimated recurrence risk. However, local regulations have to be followed. The physician is obliged to address that issue and recommended to keep written documentation of his recommendations. Counselling about safety issues regarding the behaviour in certain environments is also a very important part of the work-up and includes advice against working heights above $1 \mathrm{~m}$, unattended climbing, swimming and taking a bath, using front hotplates when cooking, slippery floor covers in the bath-room, etc. Counselling should also include the phenomenon of sudden unexpected death in epilepsy (SUDEP) [11], although that may be debatable at a low risk of recurrence.

14. Levetiracetam: Virtually no relevant interactions. Side effects: Increased irritability and other psychological disturbances; demands lower dosing in renal insufficiency.
15. Lamotrigine: Requires low starting dose and slow increase. Side effects: skin rash, most extremely in Stevens-Johnson-syndrome, interaction with paracetamol and estrogen-containing contraceptives; demands tight level-control in pregnancy.

16. If the patient cannot be admitted to hospital for diagnostics to estimate the recurrence risk after an unprovoked seizure, he may be discharged after laboratory tests and CCT with the recommendation to timely obtain an outpatient MRI, EEG and neurology consultation and should optimally re-present to a first seizure clinic.

\section{Conclusion}

The approach to a suspected first epileptic seizure in adults should start with obtaining observer information to judge that suspicion. In a second step, diagnostic work-up of the seizure should include neurologic examination, emergency blood tests, and cerebral imaging to then differentiate an acute symptomatic seizure from an unprovoked seizure. In the former, identification and -if possible- treatment of the acute underlying cause should dominate the management. In the latter, the focus should be on estimation of risk of seizure recurrence and the decision to start antiepileptic treatment.

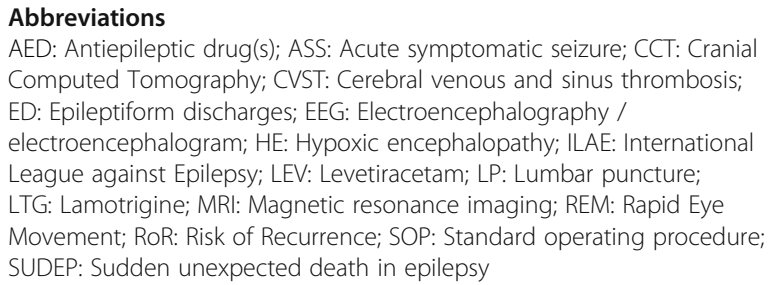

Authors' contributions

JB drafted the manuscript. The author read and approved the final manuscript.

Ethics approval and consent to participate

not applicable.

Consent for publication

not applicable.

Competing interests

The author declares that he has no competing interests.

\section{Publisher's Note}

Springer Nature remains neutral with regard to jurisdictional claims in published maps and institutional affiliations. 
Received: 17 October 2018 Accepted: 3 December 2018

Published online: 28 February 2019

\section{References}

1. Wiebe, S., Tellez-Zenteno, J. F., \& Shapiro, M. (2008). An evidence-based approach to the first seizure. Epilepsia, 49(Suppl 1), 50-57.

2. Jackson, A., Teo, L., \& Seneviratne, U. (2016). Challenges in the first seizure clinic for adult patients with epilepsy. Epileptic Disorders, 18(3), 305-314.

3. Fisher, R. S., Acevedo, C., Arzimanoglou, A., Bogacz, A., Cross, J. H., Elger, C. E. , et al. (2014). ILAE official report: A practical clinical definition of epilepsy. Epilepsia, 55(4), 475-482.

4. Fisher, R. S., Cross, J. H., French, J. A., Higurashi, N., Hirsch, E., Jansen, F. E., et al. (2017). Operational classification of seizure types by the international league against epilepsy: Position paper of the ILAE Commission for Classification and Terminology. Epilepsia, 58(4), 522-530.

5. Krumholz, A., Shinnar, S., French, J., Gronseth, G., \& Wiebe, S. (2015). Evidence-based guideline: Management of an unprovoked first seizure in adults: Report of the guideline development Subcommittee of the American Academy of neurology and the American Epilepsy Society. Neurology, 85(17), 1526-1527.

6. Seneviratne, U. (2009). Management of the first seizure: An evidence based approach. Postgraduate Medical Journal, 85(1010), 667-673.

7. Beghi, E., Carpio, A., Forsgren, L., Hesdorffer, D. C., Malmgren, K., Sander, J. W. , et al. (2010). Recommendation for a definition of acute symptomatic seizure. Epilepsia, 51(4), 671-675.

8. Herman, S. T. (2004). Single Unprovoked Seizures. Current Treatment Options in Neurology, 6(3), 243-255.

9. Crocker, C. E., Pohlmann-Eden, B., \& Schmidt, M. H. (2017). Role of neuroimaging in first seizure diagnosis. Seizure, 49, 74-78.

10. Krumholz, A., Wiebe, S., Gronseth, G. S., Gloss, D. S., Sanchez, A. M., Kabir, A A., et al. (2015). Evidence-based guideline: Management of an Unprovoked First Seizure in adults: Report of the guideline development Subcommittee of the American Academy of neurology and the American Epilepsy Society. Epilepsy Curr., 15(3), 144-152.

11. Legg, K. T., \& Newton, M. (2017). Counselling adults who experience a first seizure. Seizure, 49, 64-68.

12. Noachtar, S., \& Guldiken, B. (2017). Diagnosis of non-epileptic paroxysmal disorders and epileptic seizures. Der Nervenarzt, 88(10), 1109-1118.

Ready to submit your research? Choose BMC and benefit from:

- fast, convenient online submission

- thorough peer review by experienced researchers in your field

- rapid publication on acceptance

- support for research data, including large and complex data types

- gold Open Access which fosters wider collaboration and increased citations

- maximum visibility for your research: over $100 \mathrm{M}$ website views per year

At $\mathrm{BMC}$, research is always in progress.

Learn more biomedcentral.com/submissions 